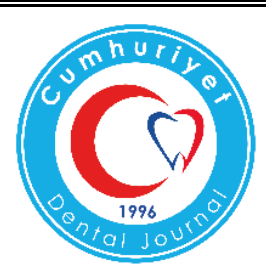

\title{
EVALUATION AND COMPARISON OF TWO COMMERCIALLY AVAILABLE MOUTHRINSES IN REDUCING AEROLISED BACTERIA DURING ULTRASONIC SCALING WHEN USED AS A PREPROCEDURAL RINSE
}

\section{ABSTRACT}

Objective: To compare and evaluate the effect of $0.2 \%$ chlorhexidine gluconate and commercially available herbal mouthrinse in reducing aerosolized bacteria when used as a preprocedural mouth rinse.

Materials and methods: A total of 45 patients were selected and randomly divided into three equal groups. As the preprocedural rinse, patients belonging to group I, group II and group III rinsed with distilled water, $0.2 \%$ chlorhexidine mouthwash $\left(\right.$ Clohex $\left.{ }^{\circledR}\right)$ and herbal mouthwash (Hiora $\left.{ }^{\circledR}\right)$, respectively, for 60 seconds. Aerosols produced during the oral prophylaxis procedure were collected on blood agar plates by exposing the plates to the patient's and dentist's chest area, and the plates were incubated at $37^{\circ} \mathrm{C}$ under aerobic conditions for $48 \mathrm{~h}$. The number of colony forming units (CFU) in the aerosol were counted and statistically analyzed.

Results: At both the locations the mean CFU were highest in Group I followed by Group III and Group II. The $0.2 \%$ chlorhexidine gluconate mouthwash was superior in significantly reducing the aerosolized bacteria during scaling, followed by herbal mouthrinse and distilled water $(\mathrm{p} \leq 0.0001)$.

Conclusions: The results of the present study clearly indicate that preprocedural rinsing with $0.2 \%$ chlorhexidine gluconate was significantly more effective than herbal mouthrinse in reducing the aerosolized bacteria during ultrasonic scaling. Therefore a preprocedural rinse can significantly reduce the risk for crosscontamination.

Keywords: Aerosols, chlorhexidine, colony count, herbal preparation.

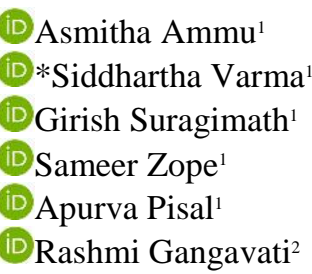

ORCID IDs of the authors: A.A. $0000-0002-3247-7175$ S.V. 0000-0001-6614-630X G.S. $0000-0002-8958-641 X$ S.Z. 0000-0002-3028-1099 A.P. $0000-0001-5801-8324$ R.G. $0000-0002-2716-3614$
${ }^{1}$ Department of Periodontology, School of Dental Sciences, KIMSDU, Karad

${ }^{2}$ Department of Oral Pathology, School of Dental Sciences, KIMSDU, Karad 


\section{INTRODUCTION}

The oral cavity is a unique environment which can provide an ideal medium for bacterial growth. Most of the procedures performed by dentists have the potential for creating contaminated aerosols and splatter, which contains bacteria, fungi, protozoa, and even bloodborne viruses produced during dental operative procedures; thus, promoting an increased risk of cross-infection. ${ }^{1}$ In dentistry, the ultrasonic scaler and the air polisher are considered to be the greatest producers of small-particle aerosol contamination. Aerosols can remain airborne for extended periods of time and may be inhaled. It was found that the microorganisms like bacteria and viruses could survive in the aerosol produced for as long as six days. ${ }^{2-6}$ The association of these aerosols with the respiratory infections, ophthalmic and skin infections, tuberculosis, and Hepatitis B have been reported. ${ }^{7}$

Current literature suggests that the use of an antimicrobial rinse by the patients before treatment may decrease microbial aerosols..$^{3-5}$ Chlorhexidine is considered as the "Gold standard" among antimicrobial rinse because of broad-spectrum antibacterial activity and high substantivity. ${ }^{3-5}$ However, it also has some side effects, like tooth staining, altered taste perception, enhanced supragingival calculus formation, and less commonly, desquamation of the oral mucosa. ${ }^{8}$ On the other hand, herbal mouth rinses with their natural ingredients can offer a safe and effective alternative to chlorhexidine, which should be optimally made use of due to their over-the-counter availability and minimal adverse effects. ${ }^{9,10}$ The benefit of using herbal preparations is that they do not contain alcohol or sugar, which are present in over-the-counter products and can cause bacterial growth resulting in halitosis or bad breath. Moreover, Hiora ${ }^{\circledR}$ mouthwash used in the current study is a formulation containing active ingredients from extracts of Salvadorapersica, Piper betel, and Terminalia bellerica which have proven to be anti-plaque agents. The current study is aimed at determining and comparing the efficacy of chlorhexidine $(0.2 \%)$ and Hiora ${ }^{\circledR}$ mouthwash in reducing the aerosol contamination produced during ultrasonic scaling.

\section{MATERIALS AND METHODS}

The present study is a double-blinded randomized clinical trial. The research protocol was approved by the institutional ethical review committee (KIMSDU/IEC/03/2015). Participants were informed about the purpose and design of the investigation and written informed consent was obtained. The patients for this study were selected from the Outpatient Department of Periodontology, School of Dental Sciences, Karad.

The subjects in the age group of 25-55 years, diagnosed with moderate form of chronic periodontitis, showing more than $30 \%$ of sites with clinical attachment loss $>4 \mathrm{~mm}$, and fulfilling the following criteria were selected for the study; patients having a minimum of 20 teeth and have not received any periodontal therapy during the past 6 months. Subjects with known systemic disease or conditions, using mouthwashes, having a history of antibiotic/anti-inflammatory therapy for three months prior to the study, pregnant and lactating women, and patients hypersensitive to chlorhexidine mouthwash were excluded.

In this study, 45 patients were randomly divided into three groups, 15 patients each, by using a computer-generated table.

Group I (control group), group II and group III patients were given distilled water, $0.2 \%$ chlorhexidine gluconate (Clohex ${ }^{\circledR}$ mouthwash, Dr Reddy's laboratories) and herbal mouthwash (Hiora ${ }^{\circledR}$ mouthwash, Himalaya), respectively, as the preprocedural rinse.

All the selected cases were subjected to ultrasonic scaling by a single operator. Prior to oral prophylaxis, a patient's periodontal status was recorded using the Gingival index ${ }^{11}$ and clinical attachment level using William's graduated periodontal probe.

The selected operatory area was fumigated prior to the study to reduce the chances of a false positive culture of airborne microorganisms. Blood agar plate was used to collect the airborne microorganisms as it is a valid medium for culturing airborne bacteria. Out of the two blood agar plates, one plate was positioned at the patient's chest area and the other at the dentist's chest area with the help of double-sided adhesive tape. An average distance of approximately 12 
inches from the patient's mouth to agar plate was maintained. Scaling was carried out with piezoelectric ultrasonic scaler along with a motorized suction. Each treatment session of ultrasonic scaling lasted approximately $30 \mathrm{~min}$.

All the patients were instructed to use the preprocedural rinse 10min before the treatment as per the group they were assigned to. Blood agar plate was left uncovered at the designated site to collect the samples of aerosolized bacteria. After collecting the sample, the blood agar plates were incubated at $37^{\circ} \mathrm{C}$ for $48 \mathrm{~h}$. The evaluation of colony forming units (CFUs) on each plate was carried out in the Department of Microbiology, Krishna Institute of Medical Sciences. The results

Table 1. Gender wise distribution of patients under three groups

\begin{tabular}{lcccccc}
\hline Gender & \multicolumn{2}{c}{ Distilled Water } & \multicolumn{2}{c}{ Herbal Mouthwash } & \multicolumn{2}{c}{$\begin{array}{c}\text { 0.2\% Chlorhexidine } \\
\text { Gluconate }\end{array}$} \\
\hline \multirow{3}{*}{ Males } & No. & $\%$ & No. & $\%$ & No. & $\%$ \\
Females & 9 & 60 & 9 & 60 & 7 & 46.67 \\
\hline
\end{tabular}

\section{Patient's chest}

It was found that the mean aerosol contamination was significantly higher in patients having distilled water (611.33CFUs) as a preprocedural were statistically analyzed using the Statistical Package for the Social Sciences (SPSS) software (version 20; IBM SPSS Inc., Chicago, IL, USA 2011). P-value $<0.05$ was considered significant. The significance in the difference in means was tested by ANOVA test.

\section{RESULTS}

The average age of the patients having distilled water, herbal mouthwash, and $0.2 \%$ chlorhexidine gluconate as a preprocedural rinse was 53.33 years, 54.67 years, and 54.60 years, respectively. The distribution of subjects according to their gender is mentioned in table1. rinse compared to patients having herbal mouthwash (380.67CFUs), followed by patients $(\mathrm{F}=281.12, \mathrm{p}<0.0001$, table 2). having $0.2 \%$ chlorhexidine gluconate (256.67CFUs)

Table 2. Comparison between reduction of aerosol contamination by pre procedural rinsing with distilled water, Herbal mouthwash and $0.2 \%$ chlorhexidine at both patients and doctors chest by ANOVA test

\begin{tabular}{|c|c|c|c|c|c|c|}
\hline \multirow[b]{2}{*}{$\begin{array}{l}\text { Descriptive } \\
\text { statistics }\end{array}$} & \multicolumn{3}{|c|}{ Patients chest } & \multicolumn{3}{|c|}{ Doctors chest } \\
\hline & $\begin{array}{l}\text { Distilled } \\
\text { Water }\end{array}$ & $\begin{array}{c}\text { Herbal } \\
\text { Mouthwash }\end{array}$ & $\begin{array}{c}0.2 \% \\
\text { Chlorhexidine } \\
\text { Gluconate }\end{array}$ & $\begin{array}{c}\text { Distilled } \\
\text { Water }\end{array}$ & $\begin{array}{c}\text { Herbal } \\
\text { Mouthwash }\end{array}$ & $\begin{array}{c}0.2 \% \\
\text { Chlorhexidine } \\
\text { Gluconate }\end{array}$ \\
\hline Mean (CFU'S) & 611.33 & 380.67 & 256.67 & 314.33 & 173.33 & 128.00 \\
\hline Std. Deviation & 47.49 & 28.15 & 46.24 & 52.67 & 29.20 & 21.11 \\
\hline Minimum & 500 & 350 & 200 & 245 & 120 & 100 \\
\hline Maximum & 675 & 450 & 350 & 400 & 200 & 150 \\
\hline F statistic & \multicolumn{3}{|c|}{281.12} & \multicolumn{3}{|c|}{104.34} \\
\hline $\mathrm{p}$ value & \multicolumn{3}{|c|}{$<0.0001^{*}$} & \multicolumn{3}{|c|}{$<0.0001^{*}$} \\
\hline t statistic & 16.22 & 19.8 & 9.8 & & & \\
\hline $\mathrm{p}$ value & $<0.0001^{*}$ & $<0.0001^{*}$ & $<0.0001^{*}$ & & & \\
\hline
\end{tabular}

The Tukey's multiple comparison test was performed to compare the difference between two pairs of means. A significant difference was observed between the groups using distilled water and herbal mouthwash $(\mathrm{p}<0.001)$; distilled water and $0.2 \%$ chlorhexidine gluconate $(\mathrm{p}<0.001)$; and herbal mouthwash and $0.2 \%$ chlorhexidine gluconate $\left(\mathrm{p} \leq 0.001^{*}\right)$.

\section{Dentist's chest}

The mean aerosol contamination was significantly higher when distilled water (314.33CFUs) was used as the preprocedural rinse compared to the herbal mouthwash group (173.33CFUs), followed by patients having $0.2 \%$ chlorhexidine gluconate (128CFUs) ( $\mathrm{F}=104.34, \mathrm{p}<0.0001$, table2).

The Tukey's multiple comparison test was performed, and a significant difference was found 
between the groups using distilled water and herbal mouthwash $(\mathrm{p}<0.001)$; distilled water and $0.2 \%$ chlorhexidine gluconate $(\mathrm{p}<0.001)$; and herbal mouthwash and $0.2 \%$ chlorhexidine gluconate $(\mathrm{p}<0.01)$.

\section{DISCUSSION}

Dental plaque is considered as one of the etiological agents in the development of periodontal disease comprising complexes of microorganisms, both bacterial and viral origin in the gelatinous matrix. ${ }^{1}$ Dental calculus is porous in nature, and it can absorb various toxic products that can damage the periodontal tissues. Hence, calculus should be accurately detected and thoroughly removed for adequate periodontal therapy. Conventional non-surgical therapy is considered to be the cornerstone of periodontal treatment ${ }^{8,9}$, including hand instruments and ultrasonic scaling. Ultrasonic produces highfrequency vibrations that lead to a phenomenon of cavitation and microstreaming. This phenomenon aids in the disruption of the bacterial cell wall as well as calculus removal. Despite the advantages of ultrasonic, there are disadvantages like tactile insensitivity and the production of aerosols. The ultrasonic scalers produce aerosols that are heavily contaminated with microorganisms and can cause a serious health threat to the patients, clinician, and the surrounding in the form of systemic conditions like common cold, influenza, tuberculosis, and severe acute respiratory syndrome (SARS). ${ }^{1}$

It is well-known that the personal protective equipment like mouth masks, head cap, eye and face shields, gloves, and gowns are most commonly used to minimize crossinfections in the dental office. However, they are not completely effective in reducing the levels of microorganisms in the environment. Furthermore, the most important drawback is that the clinician and patient remove the protective barriers shortly after completion of the treatment, whereas the aerosolized bacteria remain in the environment for up to $4 \mathrm{~h}$.

As the oral pathogens show a high probability of bypassing the host defense, adjunct therapy in the form of chemical plaque control is required to reduce the bacterial load in the aerosol. Studies have shown that ultrasonic scaling in conjunction with a preprocedural rinse containing plaque control agents was more effective in reducing bacterial loads when compared with the use of distilled water orsaline. ${ }^{5,12}$

Various mouthwashes like Listerine, Peridex, Chlorhex plus have been used in reducing the aerosol count while performing ultrasonic scaling, but, chlorhexidine is considered as a gold standard for chemical plaque control because of its good substantivity. ${ }^{3,5,13,14}$ Chlorhexidine is a bisbiguanide molecule that binds strongly to hydroxyapatite, the organic pellicle of the tooth, oral mucosa, salivary proteins, and bacteria. Chlorhexidinecontaining mouth rinses, due to the strong binding, exhibit high substantivity with $30 \%$ of the drug released after rinsing and slow release for a long time. The $0.2 \%$ chlorhexidine was the first clinically effective mouthwash that inhibited supragingival plaque formation and is highly effective against gram-positive and gram-negative organisms, yeasts, dermatophytes, and some lipophilic viruses due to its broad-spectrum antimicrobial activity. ${ }^{5,13,15}$ Several studies have indicated that chlorhexidine mouthwash is superior to herbal and essential oil mouthwashes. ${ }^{5,13,16}$

HiOra mouthwash is a nonalcoholic herbal rinse prepared from natural herbs with antibiotic, anti-inflammatory, anti-carcinogenic, and antiplaque activities. ${ }^{17}$ The use of $0.2 \%$ chlorhexidine gluconate mouthwashes as a preprocedural mouth rinsing for the duration of $60 \mathrm{~s}$ can cause a substantial reduction in bacterial counts. . $^{1,3}$ However, a study reported that herbal mouthrinse produced the largest zones of microbial inhibition compared to Listerine and $0.12 \%$ chlorhexidine. ${ }^{18}$

In the present study, blood agar plates were used to collect the airborne microorganisms as it is a valid non-selective medium for culturing airborne bacteria. Our study revealed that both the dentist and the patients were exposed to high amounts of bacteria due to aerosols produced by ultrasonic scaling. The highest number of colonies was seen on the plates positioned on the patient's chest area. The larger salivary droplets generated during dental procedures settle down rapidly with 
heavy contamination of the plates placed on the patient's chest area, followed by the contamination on blood agar placed on operator's chest area, placed 12 inches from the operating area.

The results demonstrated that the patient, operator, and people present in the operatory are exposed to a high amount of bacteria during the ultrasonic scaling procedure. The microbial load of aerosol reduced significantly in both the groups after preprocedural mouthwash usage in comparison to the control group. The analysis of the CFUs revealed that chlorhexidine was most effective in reducing the bacterial counts in the aerosol, followed by herbal mouthwash (Hiora). This could be due to the better penetration capacity of chlorhexidine into the dental plaque. These results were in accordance with other studies where the blood agar plate positioned at the patient's chest area received a greater number of microorganisms and demonstrated the efficacy of pre-procedural rinsing with chlorhexidine in reducing the aerosol contamination produced by ultrasonic scaling. ${ }^{16,19,20}$

The use of a high-volume evacuator attachment and aerosol reduction device can synergistically aid in the effective reduction of aerosol contamination without increased heat transfer to the tooth and is effective in reducing the number of microorganisms generated during ultrasonic scaling, therefore decreasing the risk of disease transmission. ${ }^{21,22}$ The results of the present study clearly indicate that preprocedural mouthrinse with $0.2 \%$ chlorhexidine gluconate was significantly effective in reducing the aerosol contamination during ultrasonic scaling in dental practice. Various studies support the results of this study, demonstrating the excellent antimicrobial effects of $0.2 \%$ chlorhexidine as a preprocedural mouth rinse in aerosol reduction. ${ }^{23,24}$ One of the limitations of the present study was considering only aerobic organisms that could be cultivated on blood agar.

\section{CONCLUSIONS}

In the present study, we found that $0.2 \%$ chlorhexidine, as an antimicrobial preprocedural mouth rinse, significantly reduced the number of microorganisms in the aerosols produced by the ultrasonic scaling units in comparison with the herbal mouthrinse. Using a preprocedural rinse significantly reduces the viable microbial content of dental aerosols.

\section{ACKNOWLEDGMENTS}

The authors would like to thank the help and support provided by the staff of the Department of Microbiology, Krishna Institute of Medical Sciences, KIMSDU, Karad in conducting the study.

\section{CONFLICT OF INTEREST}

The authors declare to have no conflict of interest.

\section{REFERENCES}

1. SwaninathanY.Thomas JT, Muralidharan NP. The Efficacy of Preprocedural Mouth Rinse Of $0.2 \%$ Chlorhexidine and Commercially Available Herbal Mouth Containing SalvadoraPersica In Reducing The Bacterial Load In Saliva And Aerosol Produced During Scaling. Asian J Pharm Clin Res 2014; 7: 71-74.

2. Acharya S,Priya H, Purohit B, Bhat M. Aerosol contamination in a Rural University Dental Clinic in South India. Int J Infect Control 2010; 6:1-7.

3. Snophia S, M.Manimegalai, Uma S, Sopia: Comparison of efficacy of preprocedural rinsing with chlorhexidine and essential oil mouth in reducing viable bacteria in dental aerosols- a microbiological study. Int J of Contemporary Dentistry 2011; 2: 1-6.

4. Bentley CD, Burkhart NW, Crawford JJ. Evaluating spatter and aerosol contamination during dental procedures. J Am Dent Assoc 1994;125: 579584.

5. Reddy S, Prasad MGS, Kaul S, Satish K Efficacy of $0.2 \%$ tempered chlorhexidine as a preprocedural mouth rinse: A clinical study. J Indian Soc Periodontol 2012;16: 213-217.

6. Saini R. Efficacy of preprocedural mouth rinse containing chlorine dioxide in reduction of viable bacterial count in dental aerosols during ultrasonic scaling: A double-blind, placebo-controlled clinical trial. Dent Hypotheses 2015; 6: 65-71.

7. Gupta G, Mitra D, Ashok, Soni S Comparison of Efficacy of Pre- Procedural Mouth Rinsing in Reducing Aerosol Contamination Produced by Ultrasonic Scaler: A Pilot Study. J Periodontol 2014; 85: 562-568.

8. Armitage GC. Periodontal diseases: Diagnosis. Ann Periodontol 1996; 1:37-215. 
9. Deepa G. Kamath, Nayak S. Detection, removal and prevention of calculus: LiteratureReview. Saudi Dent J 2014; 26: 7-13.

10. Guntaas S, Kunal K. A Comparative Evaluation of Efficacy of $0.2 \%$ Chlorhexidine with a Herbal Mouthwash as Pre-Procedural Mouthrinse in the Reduction of Aerosol Contamination Produced by Ultrasonic Scaler. Acta Scientific Dental Sciences2018; 2: 2-6.

11. Loe H, Silness J. Periodontal disease in pregnancy. I. Prevalence and severity. Acta Odontol Scand. 1963; 21: 533-551

12. Fine DH, Mendieta C, Barnett ML, Furgang D, Meyers R, Olshan A et al. Efficacy of preprocedural rinsewith an antiseptic in reducing 0viable bacteria in dental aerosol. J Periodontal 1992; 63: 821-824.

13. Logothetis DD, Martinez-Welles JM. Reducing bacterial aerosol contamination with a chlorhexidine gluconate pre-rinse. J Am Dent Assoc 1995; 126: 1634-1639.

14. Son WK, Shin SY, Kye SB, Yang SM. The effect of chlorhexidine on reduction of viable organisms in aerosol produced by ultrasonic scaler. J Korean AcadPeriodontol 2009; 39: 303-310.

15. Santos A. Evidence-based control of plaque and gingivitis. J Clin Periodontol 2003; 30 Suppl 5: 13-16.

16. Yadav S, Kumar S, Srivastava P, Gupta KK, Gupta J, Khan YS. Comparison of efficacy of three different mouthwashes in reducing aerosol contamination produced by ultrasonic scaler: A pilot study. Indian $\mathrm{J}$ Dent Sci 2018; 10: 6-10.

17. Bhat N, Mitra R, Reddy JJ, Oza S, Vinayak KM. Evaluation of efficacy of chlorhexidine and a herbal mouthwash on dental plaque: An in vitro comparative study. Int J Pharm Bio Sci 2013; 4: 625-632
18. A M Khalessi, A R C Pack, W M Thomson, G R Tompkins: An in vivo study of the plaque control efficacy of Persica: A commercially available herbal mouthwash containing extracts of Salvadorapersica. Int Dent J 2004; 54: 279-283.

19. Swaminathan Y, Toby Thomas J, Muralidharan NP. The efficacy of preprocedural mouth rinse of $0.2 \%$ chlorhexidine and commercially available herbal mouth containing salvadorapersica in reducing the bacterial load in saliva and aerosol produced during scaling. Asian J Pharm Clin Res. 2014; 7: 71-74.

20. Rani KR, Ambati M, Prasanna JS, Pinnamaneni I, Reddy PV, Rajashree D. Chemical vs. herbal formulations as pre-procedural mouth rinses to combat aerosol production: A randomized controlled study. J Oral Res Rev 2014; 6: 9-13

21. Harrel SK, Barnes J and Hidalgo FR. Reduction of Aerosols Produced by Ultrasonic Scalers. J Periodontol 1996; 67: 28-32.

22. King BT, Muzzin K, Berry CW and Anders L. The Effectiveness of an Aerosol Reduction Device for Ultrasonic Scalers. J Periodontol 1997; 68: 45-49.

23. Woo Kyung Son, Seung-Yun Shin, BeomKye and Seung-Min Yang. The effect of chlorhexidine on reduction of viable organisms in aerosol produced by ultrasonic scaler. J Korean AcadPeriodontol 2009; 39: 303-310.

24. Purohit B, Priya H, Acharya S, Bhat M, Ballal M. Efficacy of pre-procedural rinsing in reducing aerosol contamination during dental procedures. J Infect Prev 2009; 10: 190-192. 